\title{
MEMÓRIA DAS APRENDIZAGENS: UM GESTO DOCENTE INTEGRADOR DA SEQUÊNCIA DIDÁTICA
}

\section{DIDACTIC MEMORY: AN INTEGRATIVE TEACHING GESTURE OF THE DIDACTIC SEQUENCE}

\section{Eliana Merlin Deganutti Barros*}

\section{RESUMO}

Este trabalho é um recorte de uma pesquisa anterior, cujo objeto de investigação foi uma intervenção colaborativa efetuada em um $6^{\circ}$ ano de uma escola pública da periferia de Londrina. O objetivo geral da pesquisa pautou-se na validação didática da metodologia de ensino de línguas proposta por pesquisadores filiados ao Interacionismo Sociodiscursivo (ISD) em contexto específico da escolarização pública brasileira, a partir de três focos: a) os objetos/instrumentos de ensino; b) os alunos e o desenvolvimento de suas capacidades linguageiras; c) o professor no seu agir didático. A pesquisa investigou todo o processo de implementação de um projeto de escrita baseado na transposição didática do gênero "carta de reclamação", orientado pela ferramenta sequência didática (SD). Neste artigo, abordamos a teoria dos gestos didáticos - expandida por pesquisadores brasileiros filiados ao ISD - adaptada, por pesquisadores de Genebra, do conceito de gestos profissionais da Clínica da Atividade. O objetivo é apresentar resultados relativos ao agir do professor na mobilização da ferramenta SD, tomando como foco o gesto didático fundador relativo à mobilização da memória didática (ou memória das aprendizagens). Esse gesto se mostrou de suma importância no desenvolvimento da SD, pois foi responsável pela articulação entre os demais gestos didáticos fundadores, configurando-se, assim, em uma ferramenta integradora do projeto de escrita da "carta de reclamação", objeto unificador da SD desenvolvida.

Palavras-chave: sequência didática; gestos didáticos; memória das aprendizagens.

\section{ABSTRACT}

This paper is part of a larger study, whose investigation aim was a collaborative intervention involving a 6th grade teacher and students group of a public school located in the suburbs of Londrina, Brazil. The general objective of the research was the didactic validation of the language teaching methodology proposed by researchers who worked under the theoretical perspectives of the Sociodiscursive Interactionism (SDI) within specific Brazilian public school contexts. The study focused on three different aspects: a) the teaching objects/ instruments; b) the students and the development of their discursive capacities; c) the teacher in his/her didactic action. This study involved the analysis of the implementation of a writing project, which was based on the didactic transposition of the genre "letter of complaint" and oriented by the idea of the "didactic sequence" (DS) as an instrument. This

\footnotetext{
*UENP, Cornélio Procópio (PR), Brasil. edenagutti@hotmail.com
} 
paper is based on the theory of the didactic gestures, which was expanded by Brazilian researchers affiliated with SDI and adapted by researchers from Genebra, from the concept of professional gestures of the Clinic of Activity. The objective of this research is to present results related to the teacher's action as far as the mobilizations of the DS is concerned. In order to do so, focus was kept on the founding didactic gestures regarding the mobilization of the didactic memory (or learning memory). This gesture has proven to be of great importance when it comes to the development of the DS, because it was responsible for the articulation between the other founding didactic gestures and can, therefore, be considered as an integrative tool within the "letter of complaint" writing project and as a unifying object of the developed DS.

Keywords: didactic sequence; didactic gestures; didactic memory.

\section{INTRODUÇÃO}

Os resultados apresentados neste artigo são provenientes de análises de dados gerados por uma intervenção colaborativa efetuada em um contexto escolar público, que teve, como colaborador, uma professora em início de carreira e, como locus de intervenção, um $6^{\circ}$ ano de uma escola da periferia de Londrina/PR. Tal intervenção teve como objetivo desenvolver um trabalho de apropriação de uma prática linguageira configurada em um gênero de texto - a carta de reclamação -, tendo como suporte teórico-metodológico o instrumental didático proposto pelo Grupo de Genebra (pesquisadores filiados ao Interacionismo Sociodiscursivo - ISD), a fim de que ele fosse alvo de validação em contexto específico da escola pública brasileira.

A metodologia didática do Grupo de Genebra é guiada, sobretudo, por duas ferramentas que "operacionalizam" o processo da transposição didática (CHEVALLARD, 1989) de gêneros: a modelização do gênero - descrição/estudo a priori do gênero e posterior depreensão das suas dimensões ensináveis - e o procedimento sequência didática (SD) - sequência de atividades modulares projetadas para a apropriação de um gênero de texto.

A validação didática a que nos propusemos teve por finalidade investigar todo o processo da implementação do projeto didático relativo à transposição didática da carta de reclamação, articulando três elementos essenciais desse processo: os objetos/instrumentos de ensino; o desenvolvimento das capacidades linguageiras dos alunos; e o agir didático do professor. A partir desses três focos, a validação teve por objetivo não apenas "legitimar" o instrumental didático a partir da "comprovação" do desenvolvimento de capacidades de linguagem dos alunos, mas também: apontar problemas, dificuldades, sugestões de mudanças ou adaptações 
de conceitos, métodos; explicitar novas teorias, métodos que pudessem aflorar no percurso; verificar a interação do professor com essa ferramenta sob o ponto de vista dos gestos didáticos.

É sobre esse último enfoque - os gestos didáticos - que este trabalho se debruça, mais especificamente, tomando como foco um dos gestos didáticos fundadores propostos pelos pesquisadores do Grupo de Genebra: a mobilização da memória das aprendizagens (ou memória didática). O nosso objetivo é mostrar a mobilização desse gesto no desenvolvimento da ferramenta sequencia didática e a sua importância como gesto integrador do projeto de ensino da língua concretizado por esse procedimento.

Para tanto, estruturamos este artigo em seis partes: a) síntese da metodologia das sequências didáticas; b) agir profissional dos docentes: o conceito de gestos didáticos nos estudos do Grupo de Genebra; c) a sequência didática da carta de reclamação desenvolvida durante a pesquisa; d) a mobilização da memória das aprendizagens; e) análises e discussões da mobilização da memória das aprendizagens na SD da carta de reclamação e) considerações finais.

\section{A SEQUÊNCIA DIDÁTICA: FERRAMENTA DO LETRAMENTO ESCOLAR}

Assim como Dolz (2009), acreditamos que escrever se aprende escrevendo em situações "reais" - ou aproximadas desse "real" -, e isso exige tempo e projetos que tenham certo fôlego. O ISD, na sua vertente didática, visualiza o ensino da língua por meio da articulação de práticas linguageiras a um projeto de ensino de um gênero textual, concretizado no desenvolvimento do procedimento sequência didática (SD). $\mathrm{Na} \mathrm{SD}$, uma turma de alunos deve trabalhar sistematicamente, por meio de oficinas/módulos, para "resolver um problema de comunicação" (de preferência real, ou ficcionalizado pela ação didática $\left.{ }^{1}\right)$. Resolução essa que é materializada pela produção de um gênero de texto.

A SD é "uma seqüência de módulos de ensino, organizados conjuntamente para melhorar uma determinada prática de linguagem", e tem como objetivo buscar "confrontar os alunos com práticas de linguagem historicamente construídas, os gêneros textuais, para lhes dar a possibilidade de reconstruí-las e delas se apropriarem" (DOLZ; SCHNEUWLY, 2004, p. 51). As SD são "os dispositivos de organização dos conteúdos a serem 'didatizados' sobre uma prática de referência"

\footnotetext{
1 No caso do nosso projeto, o professor criou uma situação na qual os alunos perceberam a importância de se sensibilizar com os problemas da comunidade e de assumir o papel de cidadão para reclamar e solicitar a resolução desses problemas, por meio de uma ferramenta desconhecida pela maioria dos alunos: a "carta de reclamação".
} 
(NASCIMENTO, 2009a, p.69). Ela é a finalidade primeira da modelização didática dos gêneros textuais.

A partir desses modelos, constroem-se as chamadas sequências didáticas, unidades de trabalho escolar constituídas por um conjunto de atividades que apresentam um número limitado e preciso de objetivos, organizados no quadro de projeto de apropriação das dimensões constitutivas de um gênero que tem, como objetivo, estruturar as atividades particulares em uma atividade articulada em torno de um objeto [...], cujas propriedades são definidas pelo contexto sociocultural (NASCIMENTO, 2009b, p. 182).

Acreditamos que no trabalho com atividades isoladas o aluno tem mais dificuldade para conseguir integrar novas aprendizagens em relação à escrita de um gênero de texto. Portanto, o trabalho com as SD visa evitar a dispersão e sugere um trabalho intensivo, concentrado em um período limitado - que será determinado pelas condições pedagógicas de cada contexto de ensino particular, tendo como perspectiva sempre a apropriação de uma prática linguageira, o que torna inviável um trabalho aligeirado, como sugere a maioria dos livros didáticos.

A SD, conforme proposta do Grupo de Genebra, tem quatro fases: 1) apresentação da situação; 2) produção inicial; 3) módulos/oficinas; 4) produção final. A seguir, esquematizamos o procedimento $\mathrm{SD}$, a partir de adaptação da proposta de Dolz, Noverraz e Schneuwly (2004, p. 99-108):

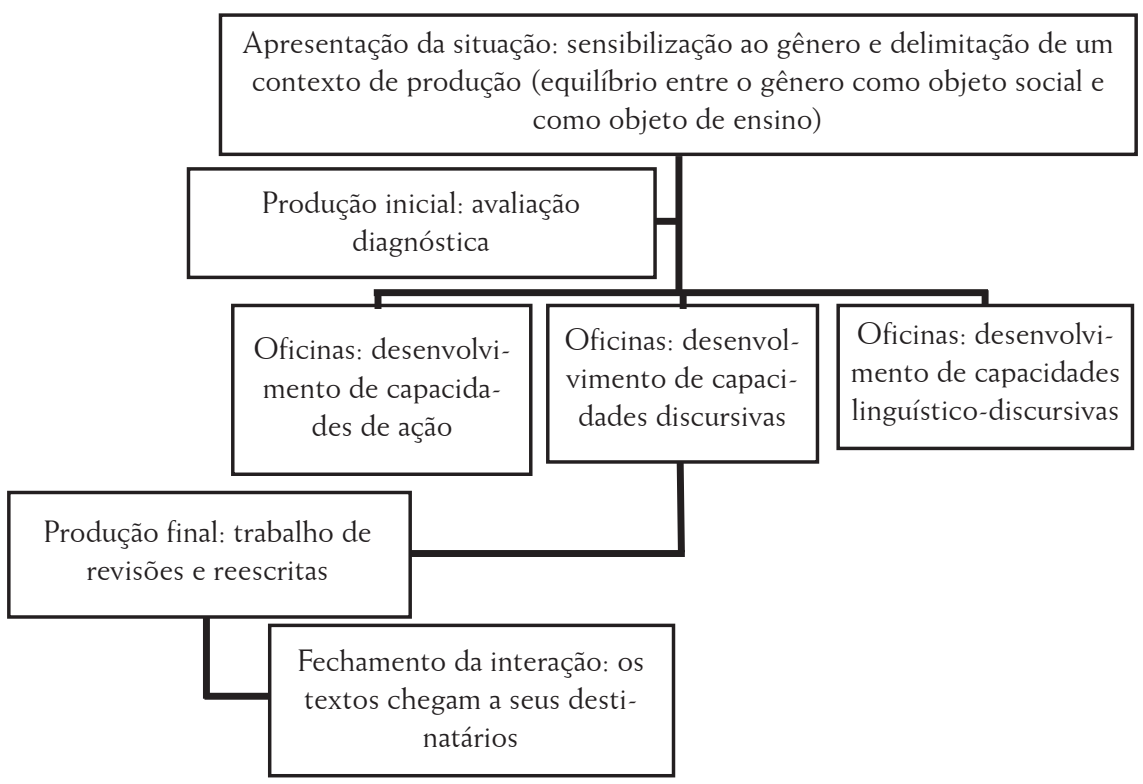

Figura 1. Esquema do procedimento sequência didática 
Como vemos, na metodologia de ensino das SD não basta apenas apresentar ao aluno um exemplar do gênero juntamente com algumas questões de interpretação como pretexto para a produção textual, como se verifica em muitos livros didáticos (cf. BARROS, NASCIMENTO, 2007), é necessário todo um trabalho sistematizado para que o aluno possa realmente apropriar-se de uma determinada prática de linguagem e não apenas tornar-se um "ledor" de textos ou um "preenchedor de linhas textuais". O trabalho com as oficinas pressupõe atividades direcionadas para o desenvolvimento de capacidades de linguagem que levem o aluno a melhorar o seu agir em relação à mobilização da prática linguageira em foco.

Por isso uma SD deve sempre propor atividades que promovam o desenvolvimento dos três tipos de capacidades de linguagem envolvidas na produção de um texto: capacidades de ação, discursivas e linguístico-discursivas. Para tanto é necessário integrar essas atividades durante a realização dos módulos para que a SD tenha o caráter de "projeto de ensino", com objetivos que se articulam, se complementam. $\mathrm{O}$ aluno precisa perceber essa unidade, a integração entre as oficinas, os seus objetos, as atividades que a compõem.

Durante a realização da nossa pesquisa colaborativa, observamos uma ferramenta importante para esse efeito integrador da SD: a mobilização da memória das aprendizagens - um gesto didático fundador no âmbito do ensino, segundo proposta de pesquisadores do Grupo de Genebra. Entretanto, para que a nossa exposição teórica tenha coerência, aprofundamos, no tópico seguinte, a noção de gestos didáticos utilizada pela nossa pesquisa.

\section{AGIR PROFISSIONAL DOS DOCENTES: OS GESTOS DIDÁTICOS}

O agir profissional do docente pode ser considerado, no campo dos estudos do ensino como trabalho, um instrumento mediador da atividade de ensinoaprendizagem. Para tratar desse instrumental didático, nos apoiamos na noção de gestos profissionais, ou gestos didáticos ${ }^{2}$ no caso específico do trabalho do professor (cf. AEBY-DAGHÉ; DOLZ, 2008; NASCIMENTO, 2011). Os gestos didáticos são movimentos discursivos e pragmáticos (NASCIMENTO, 2011) - ou seja, verbais e não verbais -, observáveis no trabalho do professor que visam sempre à aprendizagem do aluno.

2 Nesta pesquisa, estamos considerando os gestos didáticos do professor como um subconjunto dos gestos profissionais, uma vez que consideramos a atividade do professor dentro do âmbito profissional como trabalho. 
Portadores de significados, esses gestos são integrantes do complexo sistema social da atividade de ensino regida por regras e códigos convencionais, estabilizados por práticas seculares constitutivas da cultura escolar. ${ }^{3}$ (AEBY-DAGHÉ, DOLZ, 2008, p. 83).

Nesse sentido, podemos falar em duas categorias de gestos didáticos (cf. AEBY-DAGHÉ, DOLZ, 2008; NASCIMENTO, 2011): a) os gestos fundadores, relacionados às práticas estabilizadas convencionalmente pela instituição escolar, e b) os gestos específicos, relacionados às necessidades singulares impostas pela transposição didática interna de um objeto de ensino.

Sendo assim, na perspectiva adotada pela nossa pesquisa, os gestos didáticos específicos estão sempre a serviço da construção dos objetos de ensino, no processo da transposição didática. Ou seja, eles moldam-se às necessidades da didatização dos objetos escolares, assim como esses objetos vão sendo internalizados à medida que os gestos didáticos do professor vão se incorporando à atividade de ensino-aprendizagem. É nesse sentido que, na nossa pesquisa de doutoramento, fonte deste trabalho, buscamos a articulação entre a observação dos gestos didáticos específicos da professora e a construção didática do gênero "carta de reclamação" - objeto do mundo social, transposto para o ambiente didático e moldado às necessidades de um contexto de ensino-aprendizagem particular.

Acreditamos, dessa forma, assim como Aeby-Daghé e Dolz (2008), que a dinâmica das transformações dos objetos a ensinar é controlada pelos gestos didáticos: "é pelos gestos didáticos que o professor delimita o objeto, que ele o mostra, que ele o decompõe, que ele o ajusta às necessidades dos alunos, isto é, que ele o transforma em vista da aprendizagem ${ }^{4 \prime \prime}$ (p. 84).

Quanto aos gestos didáticos fundadores, Aeby-Daghé e Dolz (2008, p. 85-86), com base em suas pesquisas no contexto suíço, propõem a seguinte modelização:

1) a presentificação $0^{5}$ tem por finalidade apresentar aos alunos um objeto social de referência, no suporte adequado, que passará por um processo de didatização;

2) o apontamento/ elementarizaçãa ${ }^{6}$ (para este gesto, usamos o termo "delimitação" adotado por Nascimento, 2011) focaliza uma (ou mais) dimensão ensinável do objeto de ensinoaprendizagem - desconstrução e colocação em evidência dessa dimensão,

3 Texto original, em francês : «Porteurs de significations, ces gestes s’integrent dans le systeme social complexe de l'activité enseignante qui est rege par des regles et des codes conventionnels, stabilises par des pratiques séculares constitutives de la culture scolare».

4 Texto original em francês: «c'est par les gestes didactiques que l'enseignant délimite l'objet, qu'il le montre, qu'il le décompose, qu'il l'ajuste aux besoins des élèves, c'est-à-dire qu'il le transforme en vue de l'apprentissage. »

5 Termo usado em francês: "présentification".

6 Termos usados em francês: "pointage/élémentarisation". 
3) a formulação de tarefas: cuja porta de entrada são os dispositivos didáticos; seu estudo envolve a utilização de comandos;

4) a criação de dispositivos didáticos: os meios para enquadrar uma atividade escolar - pressupõe a mobilização de suportes (textos, esquemas, objetos reais, etc.);

5) a utilização da memória das aprendizagens: implica colocar na temporalidade o objeto de ensino e convocar as memórias das aprendizagens, para permitir utilizá-las mais tarde.

6) a regulação inclui dois fenômenos intrinsecamente relacionados: as regulações internas e as regulações locais. As regulações internas, centradas nas estratégias para obter as informações sobre o estado dos conhecimentos dos alunos (processo diagnóstico), podem estar no início, durante ou no fim de uma atividade didática (na SD, a avaliação da primeira produção do aluno é um ato de regulação didática interna). As regulações locais operam durante as atividades didáticas, em uma discussão com os alunos ou no decorrer de uma tarefa. A avaliação é considerada um gesto didático específico de regulação.

7) a institucionalização: "constituída pelos gestos direcionados para a fixação do saber (externo) que deve ser utilizado pelos aprendizes nas circunstâncias novas (internas) em que serão exigidos" (NASCIMENTO, 2011, p.427). Ela se apresenta sob a forma de uma generalização envolvendo a apresentação de informações sobre o objeto de ensino e especialmente colocando em evidência os novos aspectos desse objeto que os alunos devem aprender.

Segundo Nascimento (2011, p. 434), os gestos didáticos fundadores

\begin{abstract}
presentificam e topicalizam um conteúdo em sala de aula, fazendo emergir um sistema de gestos didáticos no interior do sistema didático, tais como: 1) a forma como o professor inicia a topicalização de um objeto novo; 2) a maneira como formula e regula as tarefas em sala de aula; 3 ) a mediação por instrumentos para regular as atividades em sala; 4 ) a maneira como institucionaliza o conteúdo.
\end{abstract}

Acreditamos que o desenvolvimento da capacidade de agir do professor se processa em uma zona de desenvolvimento potencial (cf. NASCIMENTO, 2011) em uma dialética constante entre os saberes científicos, disciplinares e didáticos da sua área. Saberes esses acumulados no processo das formações inicial e continuada, fornecidos pelo coletivo de trabalho (na forma de memória coletiva ou de textos institucionais, de cunho prescritivo) e internalizados durante a sua atividade profissional, nas execuções de tarefas exigidas pelos mecanismos da transposição didática dos objetos de ensino. 


\section{A SEQUÊNCIA DIDÁTICA DA CARTA DE RECLAMAÇÃO}

O quadro abaixo mostra uma sinopse da SD da carta de reclamação desenvolvida durante a nossa pesquisa de campo, privilegiando os objetivos traçados para cada módulo.

Quadro 1. Sinopse da SD da carta de reclamação

\begin{tabular}{|c|c|c|}
\hline \multicolumn{2}{|r|}{ Módulos } & Objetivos (para o professor) \\
\hline 01 & $\begin{array}{l}\text { Reclamação: um ato de } \\
\text { cidadania }\end{array}$ & $\begin{array}{l}\text { - Motivar os alunos para a ação } \\
\text { discursiva de reclamar } \\
\text { - Conscientizar sobre as diversas } \\
\text { formas discursivas da reclamação } \\
\text { - Conscientizar sobre a ferramenta } \\
\text { cidadã "carta de reclamação" } \\
\text { - Apresentar o Projeto Cidadania }\end{array}$ \\
\hline 02 & $\begin{array}{l}\text { Um olhar sobre os } \\
\text { problemas da comu- } \\
\text { nidade }\end{array}$ & $\begin{array}{l}\text { - Refletir sobre os problemas da } \\
\text { comunidade - tema das cartas }\end{array}$ \\
\hline 03 & $\begin{array}{l}\text { A primeira produ- } \\
\text { ção: um ensaio }\end{array}$ & $\begin{array}{l}\text { - Diagnosticar os problemas de } \\
\text { escrita em relação à carta de } \\
\text { reclamação }\end{array}$ \\
\hline 04 & $\begin{array}{l}\text { Uma pausa no Proje- } \\
\text { to Cidadania: a ne- } \\
\text { gociação das regras } \\
\text { de sala de aula }\end{array}$ & $\begin{array}{l}\text { - Mostrar a importância de se esta- } \\
\text { belecer regras para convivência } \\
\text { em sala de aula } \\
\text { - Fazer com que os próprios alunos } \\
\text { negociem e estipulem as regras } \\
\text { para a sala de aula }\end{array}$ \\
\hline 05 & $\begin{array}{l}\text { Aprendendo a dife- } \\
\text { renciar modalidades } \\
\text { diferentes de cartas }\end{array}$ & $\begin{array}{l}\text { - Trabalhar, sistematicamente, dife- } \\
\text { renças e semelhanças estruturais, } \\
\text { discursivas e contextuais entre as } \\
\text { cartas: de reclamação, comercial, } \\
\text { do leitor, pessoal e aberta }\end{array}$ \\
\hline 06 & $\begin{array}{l}\text { Reconhecendo a } \\
\text { estrutura da carta de } \\
\text { reclamação }\end{array}$ & $\begin{array}{l}\text { - Trabalhar o plano geral global da } \\
\text { carta de reclamação }\end{array}$ \\
\hline
\end{tabular}




\begin{tabular}{|c|c|c|}
\hline 07 & $\begin{array}{l}\text { Relatar ou descrever } \\
\text { o problema da recla- } \\
\text { mação? }\end{array}$ & $\begin{array}{l}\text { - Trabalhar a textualidade linguísti- } \\
\text { co-discursiva do relato e da des- } \\
\text { crição (uma das partes da carta - } \\
\text { fase da sequência argumentativa } \\
\text { responsável pela "constatação de } \\
\text { partida") }\end{array}$ \\
\hline 08 & $\begin{array}{l}\text { Começando a rees- } \\
\text { crever a carta }\end{array}$ & $\begin{array}{l}\text { - Conduzir a reescrita da carta de } \\
\text { reclamação até a parte do relato/ } \\
\text { descrição do problema }\end{array}$ \\
\hline 09 & $\begin{array}{l}\text { Aprendendo a argu- } \\
\text { mentar para deixar a } \\
\text { carta de reclamação } \\
\text { mais eficaz: opiniões } \\
\text { e argumentos }\end{array}$ & $\begin{array}{l}\text { - Trabalhar a planificação da se- } \\
\text { quência argumentativa: fase da } \\
\text { premissa (explicitação da opi- } \\
\text { nião) e apresentação dos argu- } \\
\text { mentos (com as sustentações) }\end{array}$ \\
\hline 10 & $\begin{array}{l}\text { Discutindo sobre os } \\
\text { temas das cartas }\end{array}$ & $\begin{array}{l}\text { - Fazer com que os alunos se apro- } \\
\text { fundem no problema que vão } \\
\text { reclamar para terem "argumen- } \\
\text { tos" para textualizar a carta }\end{array}$ \\
\hline 11 & $\begin{array}{l}\text { Aprendendo a usar } \\
\text { os elementos articu- } \\
\text { ladores do texto }\end{array}$ & $\begin{array}{l}\text { - Desenvolver capacidades linguís- } \\
\text { tico-discursivas nos alunos em } \\
\text { relação ao uso e funcionamento } \\
\text { dos elementos articuladores do } \\
\text { texto }\end{array}$ \\
\hline 12 & $\begin{array}{l}\text { Reescrevendo o } \\
\text { restante da carta }\end{array}$ & $\begin{array}{l}\text { - Conduzir o processo de reescrita } \\
\text { do restante da carta de reclama- } \\
\text { ção }\end{array}$ \\
\hline 13 & $\begin{array}{l}\text { Vamos aprimorar a } \\
\text { escrita da carta? }\end{array}$ & $\begin{array}{l}\text { - Conduzir processo de revisão do } \\
\text { texto, individual e em pares } \\
\text { - Conduzir o processo de reescrita } \\
\text { textual }\end{array}$ \\
\hline 14 & $\begin{array}{l}\text { Finalizando o proje- } \\
\text { to de escrita da carta } \\
\text { de reclamação }\end{array}$ & $\begin{array}{l}\text { - Orientar o processo de digitação } \\
\text { das cartas (na sala de informática) } \\
\text { - Ensinar a fazer o endereçamento } \\
\text { postal } \\
\text { - Elaborar o encerramento do pro- } \\
\text { jeto e envio simbólico das cartas }\end{array}$ \\
\hline
\end{tabular}

Essa SD é o resultado final de um processo que passou por várias reconcepções ao longo do percurso. 


\section{A MOBILIZAÇÃO DA MEMÓRIA DAS APRENDIZAGENS}

A memória das aprendizagens (ou memória didática) é um gesto didático fundador importante no ensino-aprendizagem não somente da língua, mas também de outros objetos disciplinares. Dessa forma, ele faz parte do métier do professor, consciente ou inconscientemente, e por conta disso deve ser alvo de pesquisas do agir profissional em todas as áreas de ensino.

No caso do ensino da língua, a memória das aprendizagens não é privilégio apenas da metodologia das SD. Pelo contrário, esse gesto pode ser mobilizado em qualquer procedimento didático, uma vez que, como apontam os autores genebrinos, esse é um gesto "fundador" do trabalho docente. Ele é passado de geração em geração, de um coletivo de trabalho docente a outro, geralmente pelo processo cognitivo inicial da imitação (VIGOTSKI, 2008): imitação de exprofessores da educação básica ou da graduação, de professores observados durante os estágios acadêmicos, de professores colegas de profissão. Essa imitação, com o passar do tempo, deixa de ser mecânica e passa a incorporar o métier do professor, e a tomar aspectos particulares, próprios do estilo pessoal do docente.

Embora considerando tal gesto didático como "fundador" no âmbito do agir docente, acreditamos que ele deve ser alvo de pesquisas, a fim de que possa ser objeto de discussão nos cursos de formação docente - tantos os iniciais como os de caráter continuado.

Há várias maneiras de mobilizar a memória das aprendizagens no ensino da língua. Da mesma forma, várias são as ferramentas que proporcionam a articulação deste gesto didático. O interesse principal deste trabalho é mostrar como esse gesto pode ser fundamental no funcionamento do procedimento SD que, por ser uma metodologia pautada no ensino-aprendizagem de um gênero, de forma modular, necessita de ferramentas integradoras. A memória didática, como constatado no processo de desenvolvimento das oficinas da SD, possibilita a integração dos objetos de cada módulo com o propósito geral da SD, ou seja, a apropriação de uma prática linguageira configurada em um gênero de texto. Ele possibilita a "costura", a articulação entre as "partes" do projeto de ensino materializado na SD.

A figura a seguir tenta ilustrar a metáfora da "costura" que criamos para explicar o papel do gesto de mobilização da memória didática na integração dos módulos de uma SD. 


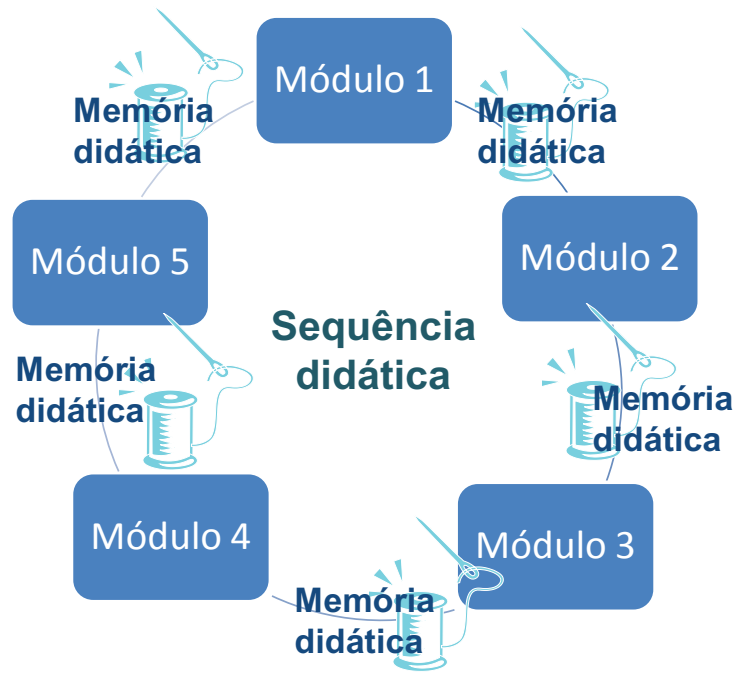

Figura 2. Metáfora da "costura": a memória didática unificando a SD

\section{A MOBILIZAÇÃO DA MEMÓRIA DAS APRENDIZAGENS NA SD DA CARTA DE RECLAMAÇÃO}

No desenvolvimento de uma SD, é de fundamental importância "capitalizar as aquisições" em relação ao gênero de referência, alcançadas durante os módulos. Nesse sentido, Dolz, Noverraz e Schneuwly (2004) apontam a importância de registrar o aprendizado sobre o gênero ao longo da SD: vocabulário técnico, regras, constatações sobre a linguagem que se realiza no gênero, sobre o planejamento textual, etc. $\mathrm{Na} S \mathrm{SD}$, esse registro configura-se como um instrumento mediador do gesto didático fundador "mobilizar a memória das aprendizagens", uma vez que ele possibilita ao professor retomar as aquisições anteriores que foram registradas para avaliar o processo de aprendizado dos alunos e articulá-las aos novos objetos de ensino da SD, assim como ao objeto unificador da SD: o gênero textual a partir do qual a SD se estrutura. 
Para os autores, esse registro pode ser em forma lista de constatações, lembrete ou glossário; pode ser construído ao longo do trabalho nos módulos ou em um momento de síntese, antes da produção final; e pode ser feito de forma individual ou coletiva pelos alunos - com mediação do professor - ou proposto diretamente pelo docente. Tudo vai depender de cada contexto específico, do gênero abordado, da dinâmica própria da classe ou do professor. $\mathrm{O}$ importante é criar esse momento de capitalização das aquisições a fim de: sintetizar, explicitar e consolidar o aprendizado; ter um material de apoio para as retomadas das aprendizagens e para o trabalho com as reescritas textuais, possibilitando o gesto da mobilização da memória didática.

A lista de constatações é, logicamente, apenas um dos instrumentos mediadores na mobilização da memória didática. O professor, a partir da sua experiência profissional, levando em conta o seu contexto específico de ensino, pode criar as suas próprias ferramentas. Alguns professores/pesquisadores trabalham com a construção progressiva das listas de constatações durante a aplicação da SD. E, na etapa de avaliação da produção final, fazem uma adaptação dessa ferramenta, transformando-a em uma ficha de avaliação em pares ou ficha de autoavaliação, a partir de questionamentos que levem o aluno a fazer a revisão e posterior reescrita do texto (questionamentos elaborados com base nos pontos levantados na lista de constatação).

$\mathrm{Na}$ nossa SD da carta de reclamação foi justamente esse o procedimento adotado. Durante a realização dos módulos, os alunos, com a ajuda da professora, foram fazendo registros das aprendizagens no caderno. No decorrer da SD, a professora, em colaboração com a pesquisadora, elaborou alguns dispositivos didáticos cujo propósito era justamente servir de registro visual das aprendizagens, uma vez que eram afixados na parede da sala e no caderno dos alunos. Já na etapa da revisão/reescrita textual os registros foram transformados, pela professora/ pesquisadora, em fichas de avaliação em pares e autoavaliação.

O registro das aprendizagens feito pelos alunos (que denominamos "relatório das aprendizagens") pode ser considerado, ao mesmo tempo, um gesto didático de regulação, ativação da memória didática e institucionalização dos objetos de ensino (gestos fundadores propostos por AEBY-DAGHÉ; DOLZ, 2008). Regulação, pois possibilita ao professor avaliar, localmente, a apreensão dos objetos didáticos trabalhados. Ativação da memória, já que opera com o resgate das aprendizagens consolidadas e como instrumento que possibilita a ativação da memória didática em momentos posteriores da SD, por ser um "registro" escrito dessas aprendizagens. Institucionalização dos objetos de ensino, uma vez que, ao resgatar as apreensões anteriores, o professor está também ativando um processo de "fixação" dos saberes subjacentes a esses objetos - saberes sociais (externos) e didatizados (internos). 
Vejamos, a título de exemplo, trechos de relatórios das aprendizagens do primeiro módulo da SD "Reclamação: um ato de cidadania" , feitos por três alunos.

A1 - "Aprendi que quando você tem uma reclamação, você tem que agir, não ficar calado(a) e não fazer nada. Você pode escrever uma carta ou conversar que tudo vai se resolver."

A2 - "Hoje eu aprendi, através do quadro púlpito, altas horas, que a gente não deve ficar calado, temos que agir, reclamar, conversar e até fazer um abaixo assinado."

A3 - "Hoje aprendi um pouco do púlpito. Os meus colegas eles protestaram, pois eles fiseram uma reclamação do que eles acham que é errado. Esse foi um geito que eu entendi."

Esses registros das primeiras impressões dos alunos auxiliaram a professora no direcionamento das atividades posteriores da SD. Eles funcionaram como um instrumento para a ativação da memória didática. Observe a fala da professora em um módulo posterior, como ela usa o registro dos alunos para refocalizar o objeto de ensino da aula anterior:

Episódio1:

P - Alguém colocou no relatório que a carta VAI RESOLVER TUDO. Não é bem assim, ela PODE RESOLVER (...)

Já os dispositivos didáticos elaborados para serem afixados nas paredes da sala e no caderno dos alunos funcionam, exclusivamente, como instrumentos mediadores da memória didática. As aprendizagens mobilizadas por eles podem ser retomadas a qualquer momento pelo professor, assim como individualmente pelo próprio aluno. São dispositivos didáticos que não mobilizam nenhuma tarefa para o aluno ou professor, além da colagem do material no caderno e nas paredes da sala. O objetivo é sintetizar o conteúdo trabalhado e deixá-lo disponível para consultas.

Como exemplo desse tipo de dispositivo, trazemos o quadro 2, afixado nas paredes da sala e no caderno dos alunos após o desenvolvimento do módulo 6 "Reconhecendo a estrutura da carta de reclamação" - como material de consulta para as atividades seguintes da SD, sobretudo, para a atividade principal da escrita da carta. Ele contém um "esqueleto" da estrutura prototípica da carta de reclamação.

7 As transcrições estão de acordo com a grafia apresentada. 
Quadro 2. Dispositivo didático mediador da memória das aprendizagens

\begin{tabular}{l} 
ESTRUTURA GERAL DA CARTA DE RECLAMAÇÃO \\
( ${ }^{*}$ Para ser afixado no caderno do aluno e na parede da sala, depois da atividade do plano \\
textual da carta de reclamação) \\
CABEÇALHO: LOCAL E DATA \\
ASSUNTO DA CARTA: PROBLEMA DA RECLAMAÇÃO \\
SAUDAÇÃO INICIAL: VOCATIVO +CUMPRIMENTOS \\
DESCRIÇÃO OU RELATO DO PROBLEMA \\
OPINIÃO / IDEIA DEFENDIDA \\
\hline \\
\hline ARGUMENTOS PARA DEFENDER A OPINIAO \\
SOLICITAÇÃO DA RESOLUÇÃO DO PROBLEMA \\
SAUDAÇÃO FINAL: DESPEDIDA \\
ASSINATURA \\
\hline IDENTIFICAÇÃO DO EMISSOR \\
\hline
\end{tabular}

A elaboração desse dispositivo foi relevante para o desenvolvimento da SD, uma vez que o objeto "plano textual global" (estrutura da carta de reclamação) teria que ser retomado nos módulos seguintes. Assim como pontuam Dolz, Noverraz e Schneuwly (2004, p. 111), "certas atividades apresentam uma base para a realização de outras". É o que acontece com o plano global do texto, ele necessita ser trabalhado logo no início da $\mathrm{SD}$, uma vez que dá uma visão de conjunto ao gênero e possibilita, posteriormente, uma articulação com os seus outros objetos de ensino da $\mathrm{SD}^{8}$. Acreditamos que a apropriação de um gênero textual mobiliza redes cognitivas de saber, articulando, de forma não linear, "recortes de aprendizagens" relativos a seus esquemas de utilização ${ }^{9}$. Isto é, pode ser que uma dimensão ensinável do gênero não

$8 \mathrm{O}$ gênero é o objeto unificador e seus esquemas de utilização são os objetos menores. Por exemplo, a sequência argumentativa é um dos objetos da SD da carta de reclamação.

9 No que se refere à gênese instrumental (RABARDEL, 1995) representada pela apropriação dos gêneros de texto (instrumentos linguageiros), os esquemas de utilização podem ser vistos, segundo Schneuwly (2004), sob dois aspectos distintos. O primeiro é "aquele que articula o gênero à base de orientação da ação discursiva" (p. 27) e o segundo é aquele que se encarrega das operações linguísticodiscursivas necessárias para a produção de um texto. 
seja internalizada em sua totalidade no momento específico da intervenção didática. Porém, quando o professor explora outro objeto desse gênero e relaciona-o ao anterior por meio da mobilização da memória didática, o aluno pode fazer articulações com o que já foi ensinado, ativar conbecimentos de mundo, antes "adormecidos", e construir uma rede cognitiva de saber que proporciona a internalização daquele objeto anteriormente visto.

A utilização desse dispositivo foi muito positiva, pois auxiliou bastante no processo de internalização do gênero e no progresso da escrita do aluno. Isso foi possível verificar pelas inúmeras vezes em que os alunos retornaram ao dispositivo para responder a algumas perguntas da professora, para resolver questões propostas nos outros módulos e, principalmente, na hora da escrita/reescrita da sua carta. A sua importância para os alunos foi verificada também, pois, em alguns momentos, os próprios alunos sentiram a falta desse dispositivo na parede, sinal de que ele era um instrumento de consulta relevante para o aprendizado do gênero.

No início, discutimos bastante, pesquisadora e professora-colaboradora, se esse dispositivo não reforçaria, em excesso, apenas a "estrutura" do gênero, desprezando as suas outras particularidades, de cunho contextual, funcional e linguístico-discursivo. Por fim, chegamos à conclusão de que o contexto em que estávamos atuando necessitava desse "modelo", pois nossos alunos, além de serem iniciantes na escrita do gênero, estavam inseridos em poucos eventos significantes de letramento, o que dificultava, por exemplo, a mobilização de conbecimentos textuais $\left(\mathrm{KOCH}_{\text {; }}\right.$ ELIAS, 2009) provenientes de gêneros semelhantes que pudessem inserir na leitura e escrita da carta de reclamação - foco do ensino da SD. Vimos também, no decorrer das atividades seguintes, que essa visão textual global do gênero é fundamental para a institucionalização e internalização dos demais esquemas de utilização do gênero. $\mathrm{O}$ episódio a seguir, ponto de articulação entre o módulo 06 e 07, demonstra bem como a visão global da estrutura da carta de reclamação auxilia a professora a presentificar o próximo objeto - o relato ou descrição do problema - assim como iniciar a sua institucionalização didática.

\section{Episódio 2:}

P - ((Pega o dispositivo do plano textual global da carta da parede e vai ao quadro e desenha a estrutura da carta de reclamação, discriminando as suas partes)) Pessoal, por que eu fiz isso aqui?

P - Hoje tem uma parte da carta que a gente vai estar explicando para vocês para vocês fazerem a carta / hoje nós vamos ver esse ponto aqui ((Vai até o quadro e grifa a parte do relato ou descrição do problema))

$\mathrm{P}-\mathrm{O}$ que nós vamos ver hoje? 
As - O relato ou a descrição do problema

$\mathrm{P}$ - A gente vai estudar sobre a diferença entre o relato e a descrição, porque vocês vão ter que relatar ou descrever o problema que escolheram para a carta de vocês

Nesse episódio, podemos perceber que a professora situa o esquema de utilização do gênero que vai começar a explorar na configuração geral do plano textual global do gênero - objeto já explorado em módulo anterior, mobilizando, assim, um gesto didático referente à memória das aprendizagens. A partir desse gesto, a professora consegue estabelecer uma unidade ao projeto de escrita da carta de reclamação: um novo objeto (relato/descrição) tem relação direta com o visto anteriormente (plano textual global da carta de reclamação). Os alunos passam a perceber que as atividades, mesmo não trabalhando diretamente com a carta de reclamação (como são as atividades do módulo sobre relato/descrição), estão desenvolvendo capacidades para a escrita desse gênero.

Na finalização do módulo 6 e início do 7 , a professora também faz uma articulação direta com a escrita da carta do aluno, dando, como já dito anteriormente, uma unidade ao projeto de ensino da escrita. Quando, por exemplo, a professora lê a parte da "descrição ou relato do problema" no dispositivo da estrutura da carta (quadro 2), ela pergunta aos alunos:

\section{Episódio 3:}

$\mathrm{P}$ - no caso da carta de reclamação que vão escrever é um relato ou descrição de que problema?

As - ((Cada um fala o seu problema da carta, ao mesmo tempo) $)$

Quando lê a parte da "assinatura e identificação do emissor":

\section{Episódio 4:}

$\mathrm{P}$ - Quem é o emissor da carta de vocês?

As - Nós / eu

P - A identificação do emissor é só o RG? ((Em uma das cartas trabalhadas no módulo 6, o emissor se identifica com o RG))

As - NÃO

A1 - Pode colocar o endereço ((Em duas das cartas trabalhadas no módulo 6, o emissor se identifica com o endereço))

$\mathrm{P}$ - Quem é o emissor?

A2 - Quem escreve

P - Por exemplo, na carta que o Gabriel vai escrever ele pode colocar aluno da quinta série da escola (...)? ((Diz o nome da escola)) 
As - PODE

(...)

$\mathrm{P}-\mathrm{O}$ assunto / explicitar o assunto não é obrigatório / mas no corpo da carta tem que aparecer

Nesses episódios é possível perceber como a professora aciona a memória das aprendizagens em relação ao contexto de produção do gênero, fazendo uma articulação com o objeto do módulo - plano textual global da carta de reclamação - e o próprio texto do aluno. Esse gesto específico de articulação entre o objeto de ensino em foco e a produção textual do aluno, a partir da mobilização da memória didática, faz com que o aluno perceba a diferença de ter de escrever uma mera "redação" escolar, desprovida de gênero, de características próprias, de coerções contextuais ligadas ao seu uso social, e produzir um texto, de um gênero específico, fruto de um trabalho sistemático de aprendizado. Dessa forma, é possível perceber como a mobilização da memória didática é essencial para a unicidade do projeto de ensino da SD e, consequentemente, para o seu sucesso como metodologia de ensino da língua, baseada em um evento de letramento específico.

Enfim, o gesto fundador de ativação da memória das aprendizagens proporciona, no desenvolvimento da SD, uma "articulação" necessária à completude do projeto de ensino. Essa articulação se dá em vários níveis, entre o objeto de um módulo e outro, entre o objeto de um módulo e a produção textual do aluno, etc. $\mathrm{O}$ quadro 3 traz uma síntese desses gestos didáticos específicos que são ancorados no gesto fundador da mobilização da memória didática.

Quadro 3. Gestos didáticos articuladores da SD e a mobilização da memória didática

\begin{tabular}{|l|l|}
\hline $\begin{array}{l}\text { Gesto de articular } \\
\text { as três capacidades } \\
\text { de linguagem } \\
\text { no processo de } \\
\text { desenvolvimento } \\
\text { de uma SD }\end{array}$ & $\bullet \begin{array}{l}\text { É um dos gestos didáticos específicos } \\
\text { mais relevantes no desenvolvimento de } \\
\text { uma SD. Faz com que o aluno perceba } \\
\text { a unidade do projeto de escrita. }\end{array}$ \\
\hline $\begin{array}{l}\text { Gesto de } \\
\text { articulação entre } \\
\text { um módulo e outro }\end{array}$ & $\begin{array}{l}\text { É um gesto que ajuda a proporcionar } \\
\text { o sucesso da SD, pois faz a integração } \\
\text { do projeto da escrita. Foi muito comum } \\
\text { a professora, para iniciar um módulo, } \\
\text { articulá-lo ao anterior para dar coerên- } \\
\text { cia ao projeto. }\end{array}$ \\
\hline
\end{tabular}




\begin{tabular}{|l|l|}
\hline $\begin{array}{l}\text { Gesto de } \\
\text { articulação entre } \\
\text { o objeto de ensino } \\
\text { em foco no módulo } \\
\text { e a produção } \\
\text { textual do aluno }\end{array}$ & $\begin{array}{l}\text { No nosso caso, a professora faz uma } \\
\text { articulação entre o objeto "relato/des- } \\
\text { crição do problema" com a escrita da } \\
\text { carta de um aluno, sem que isso tenha } \\
\text { sido alvo de planificação do seu traba- } \\
\text { lho docente. }\end{array}$ \\
$\begin{array}{l}\text { Esse gesto auxilia o aluno a refletir } \\
\text { sobre a sua escrita e a perceber que os } \\
\text { conteúdos trabalhados têm um propósi- } \\
\text { to: ajudá-lo na escrita do seu texto. }\end{array}$ \\
\hline $\begin{array}{l}\text { Gesto de partir } \\
\text { do plano textual } \\
\text { global para fazer a } \\
\text { institucionalização } \\
\text { dos outros } \\
\text { esquemas de } \\
\text { utilização do } \\
\text { gênero }\end{array}$ & $\begin{array}{l}\text { Esse é um gesto didático que deve ser } \\
\text { mobilizado constantemente no desen- } \\
\text { volvimento de qualquer SD. O plano } \\
\text { geral do gênero é um esquema de uti- } \\
\text { lização que deve ser mobilizado nos } \\
\text { primeiros módulos, pois dá uma visão } \\
\text { de conjunto ao gênero. Sendo assim, ele } \\
\text { pode ser a espinha dorsal dos esquemas } \\
\text { de utilização do gênero tomados como } \\
\text { objetos de ensino posteriormente. }\end{array}$ \\
\hline $\begin{array}{l}\text { Gesto de } \\
\text { articulação entre o } \\
\text { objeto delimitado } \\
\text { no módulo e o } \\
\text { gênero focado pelo } \\
\text { projeto da escrita }\end{array}$ & $\bullet \begin{array}{l}\text { Esse gesto é fundamental para o desen- } \\
\text { volvimento de qualquer SD. }\end{array}$ \\
$\begin{array}{l}\text { Faz com que o aluno perceba o trabalho } \\
\text { sistemático de aprendizado que é preci- } \\
\text { so para se chegar à escrita de um texto } \\
\text { (não de uma redação escolar). }\end{array}$ \\
\hline
\end{tabular}

\section{CONSIDERAÇÕES FINAIS}

A mobilização da memória das aprendizagens se revelou um gesto fundador essencial na articulação geral da SD, uma vez que, por meio dele foi possível fixar conteúdos já trabalhados (institucionalização), efetuar a regulação do aprendizado, articular objetos de ensino já institucionalizados com objetos em processo de delimitação, retomar a presentificação do objeto social em foco, auxiliar o encaminhamento das atividades e tarefas. Esse é um gesto que, com certeza, deveria ser foco de reflexão nos cursos de formação docente. Entendemos que os gestos didáticos precisam ser objeto de ensino nos cursos de formação inicial e continuada, mas não com o objetivo de "engessá-los" a formas "certas" ou "erradas", mas de colocá-los em evidência como foco de debates, como elementos essenciais do trabalbo docente. 


\section{REFERÊNCIAS BIBLIOGRÁFICAS}

AEBY-DAGHÉ, S.; DOLZ, J. (2008). Des gestes didactiques fondateurs aux gestes spécifiques à l'enseignement-apprentissage du texte d'opinion. In: BUCHETON, Dominique; DEZUTTER, Olivier (Org.). Le développement des gestes professionnels dans l'enseignement du français: un défi pour la recherche et la formation. Bruxelas: De Boeck, p.83-105.

BARROS, E. M. D. de; NASCIMENTO, E. L. (2007). Gêneros textuais e livro didático: da teoria à prática. Linguagem em (Dis)curso, Tubarão/SC, v.7, n.2, p.241-270.

CHEVALLARD, Y. (1989). On didactic transposition theory: some introductory notes. Disponível em: $\quad<$ http://yves.chevallard.free.fr/spip/spip/rubrique.php3?id_rubrique $=6>$. Acesso em: 17 jan. 2011.

DOLZ, J. (2009). Claves para ensenar a escribir. Leer.es, Espanha. Disponível em: < http:// leer.es/detalle-buscador/?id=968\&bid=8>. Acesso em: 12 abril 2011.

DOLZ, J.; NOVERRRAZ, M.; SCHNEUWLY, B. (2004). Seqüências didáticas para o oral e a escrita: apresentação de um procedimento. In: SCHNEUWLY. B.; DOLZ, J. (Org.). Gêneros orais e escritos na escola. Trad. de Roxane Rojo e Glaís Sales Cordeiro. Campinas: Mercado de Letras, p. 95-128.

DOLZ, J.; SCHNEUWLY, B. (2004). Gêneros e progressão em expressão oral e escrita - elementos para reflexões sobre uma experiência suíça (francófona). In: SCHNEUWLY, B.; DOLZ, J. (Org.). Gêneros orais e escritos na escola. Campinas: Mercado das letras, p. 41-70.

KOCH, I. V.; ELIAS, V. M. (2009). Ler e escrever: estratégias de produção textual. São Paulo: Contexto.

NASCIMENTO, E. L. (Org.) (2011). A dupla semiotização dos objetos de ensinoaprendizagem: dos gestos didáticos fundadores aos gestos didáticos específicos. Signum: Estudos da Linguagem, Londrina, v. 14, n.1, p. 421-445.

(2009a). Gêneros textuais: da didática das línguas aos objetos de ensino. São Carlos: Claraluz.

(2009b). Gêneros escolares: das práticas de linguagem aos processos de desenvolvimento humano. In: FERNANDES, L. C. (Org.). Interação: práticas de linguagem. Londrina: EDUEL, 2009b.

RABARDEL, P. (1995). Les Hommes et les technologies: une approche cognitive des instruments contemporains. Paris: Université de Paris 8. Disponível em: <http://ergoserv. univ-paris8.fr/site/groupes/modele/articles/public/art372105503765426783. pdf $>$. Acesso em: 05 jan. 2010.

SCHNEUWLY, B (2004). Gêneros e tipos de discurso: considerações psicológicas e ontogenéticas. In: SCHNEUWLY, B.; DOLZ, J. (Org.). Gêneros orais e escritos na escola. Trad. Roxane Rojo e Glaís Sales Cordeiro. São Paulo: Mercado das Letras, p. 21-39.

VIGOTSKI, L. S. (2008). Pensamento e Linguagem. Trad. Jefferson L. Camargo. 4. ed. São Paulo: Martins Fontes. 
Apêndice

Lista dos códigos da transcrição das aulas

\begin{tabular}{|c|c|}
\hline CÓDIGO & OCORRÊNCIA \\
\hline $\mathrm{A} 1, \mathrm{~A} 2, \mathrm{~A} 3$ & Alunos \\
\hline As & Vários alunos \\
\hline $\mathrm{P}$ & Professora colaboradora \\
\hline $\mathrm{Pq}$ & Pesquisadora \\
\hline “' & Leitura de trechos escritos \\
\hline$\ldots$ & Pausa longa \\
\hline , & Pausa curta \\
\hline$(\ldots)$ & Recorte de trechos \\
\hline$[[$ & Simultaneidade de vozes \\
\hline (incompreensível) & Incompreensão de palavras ou segmentos \\
\hline$(())$ & Comentários da pesquisadora \\
\hline MAIÚSCULA & Entonação enfática \\
\hline 1 & Truncamento de palavras ou desvio sintático \\
\hline- & SI-LA-BA-ÇÃO \\
\hline " " & Citações de falas de terceiros \\
\hline$?$ & Entonação correspondente à pergunta \\
\hline$!$ & Entonação exclamatória \\
\hline
\end{tabular}

Recebido: 07/09/2012

Aceito: 28/04/2013 